\title{
Chapter 19 \\ Higher Education Innovations: Hong \\ Kong, China; the Republic of Korea; \\ and Indonesia
}

\author{
Gerard Postiglione
}

Higher education plays a critical role not only in human capital development and nation building, but also in innovation systems. A lot of countries have recognized the pivotal role of universities and higher education institutions in achieving a knowledge-based economy. Anticipating emerging opportunities brought by globalization and technological advancements, many universities all over the world scramble to produce competitive graduates that will be able to thrive both in the national and the global labor markets.

\section{Issues and Challenges}

Rapid technological development brought about by the Fourth Industrial Revolution is changing the landscape of skills and employment around the world. This puts more pressure on educational institutions to quickly adapt and formulate innovative strategies to cope with disruptions and possible threats posed by these technological advancements. Further, with the rise of scientific breakthroughs and technological developments, it has been suggested that a country has at least one world-class research university to benefit from these developments. ${ }^{1}$

However, world-class universities have different emphases and approaches, as well as procedures and mechanisms. There is no universal ideal model or formula

\footnotetext{
${ }^{1}$ ADB. 2014. Innovative Strategies in Higher Education for Accelerated Human Resource Development in South Asia. Asian Development Bank. Manila; Philip G. Altbach and Jamil Salmi. 2011. The Road to Academic Excellence: The Making of World-Class Research Universities. IBRD/World Bank. Washington DC.
}

\section{G. Postiglione ( $\varangle)$}

Higher Education, The University of Hong Kong, Pok Fu Lam, Hong Kong, China e-mail: gerry.hku@gmail.com 
to achieve such status, given that successful universities and/or institutions developed under different contexts in which leaders and decision-makers took advantage of emerging opportunities. Simply copying models used in other countries may also be counterproductive and ineffective. Instead, experiences from countries with successful higher education institutions may provide lessons and partial instruction. ${ }^{2}$

\section{Proposed Solutions}

To be more competitive and innovation-driven, high-quality universities need (i) competent faculty; (ii) good research, curricula, and pedagogy; (iii) good students; (iv) sufficient funding; and (v) adequate facilities. ${ }^{3}$ Developing countries particularly need to place high importance on building talent (whether from inside or outside of the country). Recruiting and retaining leading academics is a key catalyst. The internationalization of universities can help attract top-caliber faculty to diversify university capacity and contribute to institutional upgrading and the strengthening of graduate studies and research.

Another important strategy is productive collaborations with other universities, especially those in developed countries. International collaborations provide the venue for student and faculty mobility, as well as for sharing of resources and ideas. ${ }^{4}$ Such partnerships include establishing dual-degree programs, collaborating in research projects, and engaging with global knowledge networks.

\section{Examples of Good Practices}

\section{Developing a World-Class University: The Case of the Hong Kong University of Science and Technology}

Hong Kong, China has several of the world's top 50 universities and more in the world's top 100 according to the Times Higher Education's ranking. In the 1980s, Hong Kong, China, along with the Republic of Korea (ROK), Singapore, and Taipei,China were called the Four Dragons of Asia because of their common cultural heritage, open economies, and rapid growth. In the 1990s, the governments of the ROK, Singapore, and Taipei,China began to upgrade their economies by investing in value-added high-tech manufacturing. Hong Kong, China's laissez fair philosophy

\footnotetext{
${ }^{2}$ Cheng, Ying; Wang, Qi; Cai Liu, Nian. (eds.) 2014. How World-Class Universities Affect Global Higher Education Influences and Responses. Sense Publishers. Rotterdam.

${ }^{3}$ Park, Sung Joo. 2016. How to Innovate Higher Education in Developing Countries?. Presented at the 2016 ADB International Skills Forum.

${ }^{4}$ Wang, Qi; Cheng, Ying; Cai Liu, Nian. (eds.). 2013. Building World-Class Universities: Different Approaches to a Shared Goal, 1-10.2013. Sense Publishers. Rotterdam.
} 
of economic development provided infrastructure but less investment for high-tech manufacturing. That infrastructure included the Hong Kong Research Grants Council (RGC), opened in 1988, to provide large-scale competitive research grants to universities. It coincided closely with the establishment of Hong Kong University of Science and Technology (HKUST) in 1991.5

1. As government support for research became enlarged with the creation of HKUST, funding to each university in Hong Kong, China was still disbursed on a competitive basis by the Universities Grants Committee (UGC), a nonstatutory body that advises the Government on the funding and strategic development of higher education. Resources allocated to the creation of HKUST as a new university were not to the disadvantage of allocations to other universities. The UGC recommendations to government reflect an effort to ensure complementarity among universities while strengthening their respective research capacities. The RGC also provides competitive grants to encourage interuniversity collaborative research directed at key challenges.

As a new university, HKUST was well-funded with a strong focus on science and technology and a competitive business education program, capitalizing on its location in a commercial city. The university entered Asia's top 10 university rankings within 10 years of its establishment. It currently ranks 30th in the world, 2nd among universities less than 50 years old, 3rd among all Asian universities, and 12th in the world on employability of graduates. Nearly $99 \%$ of its graduates get employed upon graduation. HKUST also ranked 1st in executive MBA programs for the last 8 years.

HKUST maintains its world-class status with a high degree of institutional autonomy and academic freedom. From the start, it has been able to strategically capitalize on opportunities and advantageous conditions. With a vision to be "unique and not duplicate," HKUST has distinguished itself from other mainstream universities by finding a niche and building collaborations across disciplines and institutions. It places equal importance on research and high-quality teaching. It has no undergraduate degree in the social sciences or humanities. Yet, it requires all of its students in science, technology, and business studies to take social science and humanities courses as a way to drive innovative thinking. The university adopts a unique entrepreneurial research culture that promotes transfer and commercialization of technologies. ${ }^{6}$ HKUST has notably invested in recruiting outstanding local and international faculty, scholars, and scientists. Particularly, it has recruited heavily from Chinese academics who studied and worked at world-class universities

\footnotetext{
${ }^{5}$ Postiglione, G. A. 2011. The Rise of Research Universities: The Hong Kong University of Science and Technology. In Altbach, P. G. and Salmi, J., The road to academic excellence: the making of world-class research universities (pp. 63-100). Retrieved from http://siteresources.worldbank.org/EDUCATION/Resources/278200-109907987 7269/547664-1099079956815/547670-1317659123740/Chapter3.pdf; Postiglione, G. A. 2013. Anchoring globalization in Hong Kong's research universities: Network agents, institutional arrangements, and brain circulation. Studies in Higher Education, 38(3), 345-366.

${ }^{6}$ Ibid.
} 
overseas. This not only ensures quality teaching, but also helps build transnational collaborations and attract international research funding.

HKUST's lessons learned and its keys to success can be summarized as follows: (i) pay attention to global trends and regional opportunities; (ii) move from global linkages to innovative interdependencies; (iii) forge collaborations with industry that are sustainable; (iv) leverage innovative regional exchanges; (v) nurture entrepreneurial talent; (vi) know the region, its universities, government, and the possibilities; (vii) embrace the competition and collaborate; (viii) position within the system as a catalyst; (ix) consider the medium of instruction; (x) be innovative in governance; (xi) hire the best human resources; (xii) set the conditions for a dynamic working environment; (xiii) attract research funding and donations; and (xiv) build a model that maximizes the transfer and commercialization of knowledge.

\section{Universities for the Digital Age: The Case of the State University of New York Korea and KAIST Business School}

The ROK has been a key player in the digital revolution since the 1980s, when it was at the forefront of the telecommunications industry. The country has become a rising star in technological advancements, surpassing other developed countries. As a result, the gross national income per capita in the ROK increased through the years. Recognizing the role of education, science and technology, and innovation in its rapid economic growth, the ROK has placed importance on these sectors to pursue industrialization and transition into a knowledge-based economy.

The Korean Government invited the State University of New York (SUNY) to establish a global campus in an effort to pursue academe-government-industry collaboration. ${ }^{7}$ Strategically situated in the Incheon Free Economic Zone (IFEZ) and the ROK's smart city, Songdo, SUNY Korea is the first joint global and American university in the country. The campus' establishment was funded by the ROK, particularly by the central Government and the Incheon City metropolitan government. Aside from government support, SUNY Korea also forged collaborations with global companies and institutions in terms of internship and employment opportunities. The Incheon Global Campus has since expanded to 64 campuses around the world. Through these "extended campuses," Korean students get the same course content from partner universities around the world.

Another successful and internationally renowned research university established by the Korean Government together with American policymakers is Korea Advanced Institute of Science and Technology (KAIST). Likewise, KAIST makes a concerted effort to pursue internationalization through dual-degree programs and research collaborations with international universities. It also has strong university-industry

\footnotetext{
${ }^{7}$ Kao, I., Shamash, Y. A., and Kim, C. 2013, June. Establishing an American Global Campus in SUNY Korea: Challenges and Excitement in Preparing Global Engineers Paper presented at 2013 ASEE International Forum, Atlanta, Georgia. https://peer.asee.org/17228.
} 
linkages to promote technology transfer and foster cutting-edge ventures. Moreover, KAIST values the importance of competent talent to maintain excellence in the university - as a strategy, they actively recruit foreign faculty, and invite talented retirees from academe and industry to teach. To fully embrace their thrust of being an international organization and attract more international students, around $85 \%$ of KAIST's courses are taught in English. ${ }^{8}$

\section{University Strategic Partnerships: Institut Teknologi Bandung Indonesia}

The Institut Teknologi Bandung (ITB), Indonesia's top university, was founded in 1920. It has 25,000 students and more than 1000 faculty and staffs. The different faculties are divided into four clusters: (i) Science; (ii) Engineering; (iii) Arts and Design; and (iv) Business and Management. ITB ranks 331st in the 2017 Quacquarelli Symonds World University Rankings, and 62nd in Asia.

ITB actively partners with several universities, research institutes, industry, government, and communities. It has notably collaborated with more than 350 foreign universities and research institutes from more than 40 countries. ITB maintains these global linkages to (i) promote mobility of faculty and students (ii) attract internationally diverse students, (iii) improve the curriculum through collaborative teaching and collaborative research networks, (iv) promote innovation, (v) enhance industry exposure, and (vi) raise its international profile and reputation. Some partnerships are internally driven, which means faculties and departments initiate the move. Others are externally driven when overseas partners seek ITB's participation or a mix of both external and internal efforts.

It is also worthy to note that ITB has more than 300 industry partners. Around $25 \%$ of ITB's operational budget comes from industry contributions. By acknowledging that companies have different areas of interests for investments, ITB engages in various kinds of partnerships. For example, with the Institute for Innovation and Entrepreneurship Development (IIED) to institutionalize innovation and an entrepreneurial spirit in the university, ITB has managed to create 70 start-ups and 6 spin-off companies.

As ITB continues to pursue excellence, it reaps multiple benefits from partnerships. Through partnerships, it has been able not only to learn and share knowledge and expertise, but also to benchmark standards. The experience has highlighted the importance of considering both medium- and long-term interests from both parties when engaging in such collaborations. Partners need time to get to know each other, and universities should be prepared for possible internal changes that periodically

\footnotetext{
${ }^{8}$ Times Higher Education. 2016. Korea's Internationalization Challenge: An interview with the president of the Korea Advanced Institute of Science and Technology. Retrieved from https://www.insidehighered.com/news/2016/04/21/interview-president-korea-advanced-ins titute-science-and-technology.
} 
occur in leadership, staffing, funding arrangements, and institutional strategy. Partnerships should have a clear focus and realistic targets/commitments. Lastly, in pursuing prospective collaborations, it is important to allocate time and resources to research potential partners.

\section{The Swiss Model of Partnership in Higher Education: ETH Zurich}

Switzerland invests in international collaborations through its Education, Research, and Innovation (ERI) strategy. This includes the Swiss National Science Foundation (SNSF), which provides funding for joint research projects, scientific exchange visits, and workshops/conferences in collaboration. with others (e.g., Argentina; Brazil; Hong Kong, China; India; Japan; People's Republic of China; the Republic of Korea; the Russian Federation; South Africa; and Taipei,China). Scholarships for PhD and postdoctoral studies are also available through the Swiss Government Excellence Programme. The State Secretariat for Education, Research and Innovation (SERI) also funds bilateral programs that invite Swiss universities and research institutions to partner with institutions from other economies. These bilateral programs are managed by the selected Swiss universities, which are called "leading houses." For instance, ETH Zurich is the leading house for the bilateral science and technology cooperation program of Switzerland with Hong Kong, China; Japan; the People's Republic of China; the Republic of Korea; Taipei,China; and members of the Association of Southeast Asian Nations.

ETH Zurich is an autonomous and well-funded university that was founded in 1855 to be the driving force of industrialization in Switzerland. It is highly reputable and internationally recognized, as the university consistently ranks among the top 5 in Europe and in the top 10 globally. ETH Zurich's bilateral programs consist of (i) Bridging Grants or Seed Money Projects for joint projects; (ii) Mobility Grants for doctoral and postdoctoral candidates; (iii) Innovation Programs, such as 3-month Asia Industry Internships, Innovation Partnership Grants (joint activity between Swiss academic partners and innovation partners in Asia), and Asia Entrepreneurship Training (training for start-ups with Asia-experienced entrepreneurs); and (iv) Strategic Topics and Exploratory Funding (e.g., strategic planning workshops, topical conferences, or funding to respond to emerging opportunities).

To foster an entrepreneurial spirit, ETH put in place various mechanisms to assist students and researchers at all stages of development (research, proof of concept, prototype, product development, and product). At the research stage, the university has put up the Spark Award to recognize the best patents. As proof of ETH's concept of product development, there is an ieLab (Innovation and Entrepreneurship Laboratory) that provides networking opportunities for entrepreneurs and venture capitalists to support young researchers and bring their technology to the market. At the product stage, there is ETH's spin-off, which has launched 25 start-ups. These start-ups have an amazing $90 \%$ survival rate after 5 years. 


\section{Application of These Good Practices}

The good practices outlined in this brief paper may not always be easily replicated. Good practices are developed at particular moments in time and within particular local contexts. Yet, they provide thoughtful lessons about how experimentation with key elements can result in successful adaptations to achieve success. The common features of these good practices are undeniable. They include investing in competent talent, placing an emphasis on international collaborations, and fostering government-academe-industry linkages. Most importantly, these models are successful because they remain nimble enough to quickly capitalize on emerging opportunities and conditions, while finding their niches and formulating innovative practices.

\section{Implications for the Future}

As the rise of frontier technologies and the Fourth Industrial Revolution is expected to profoundly reshape the demand for skills of the labor market, education systems are compelled to produce lifelong learners who have the flexibility and learning ability to quickly adapt to rapid technological progress. ${ }^{9}$ This entails equipping students with twenty-first-century skills (a combination of foundational literacies, competencies, and character qualities) that fostering their capacity to innovate. Continuing, lifelong, and adult education also need to be strengthened in order to provide opportunities for reskilling and/or upskilling in anticipation of changes in the employment landscape.

Higher education curricula will have to develop not only technical acumen/mastery, but also intercultural and socioeconomic skills among learners. ${ }^{10}$ A World Bank study suggests that, aside from educational attainment, having both cognitive skills and noncognitive skills (e.g., social intelligence and creativity) will be fundamental in avoiding automation-prone occupations. ${ }^{11}$ Government-academeindustry linkages will also be crucial to help the education system to quickly receive labor market information and respond to the emerging skills needs of the economy.

\footnotetext{
${ }^{9}$ United Nations Department of Economic and Social Affairs (UNDESA). 2017. The impact of the technological revolution on labor markets and income distribution. Retrieved from https://www.un. org/development/desa/dpad/wp-content/uploads/sites/45/publication/2017_Aug_Frontier-Issues1.pdf.

${ }^{10}$ Penprase B. E. 2018. The Fourth Industrial Revolution and Higher Education. In: Gleason N. (ed.) Higher Education in the Era of the Fourth Industrial Revolution. Palgrave Macmillan, Singapore.

${ }^{11}$ Bentaouet Kattan, R.; Macdonald, K. A. D.; Patrinos, H. A. 2018. Automation and labor market outcomes: the pivotal role of high-quality education (English). Policy Research working paper; no. WPS 8474. Washington, DC: World Bank Group. Retrieved from http://documents.worldbank. org/curated/en/356581528983322638/Automation-and-labor-market-outcomes-the-pivotal-roleof-high-quality-education.
} 


\section{Conclusion}

With the advent of the Fourth Industrial Revolution, universities and higher education institutions are the key players in preparing a labor force and for having a significant impact on social and economic progress. There is a need to scale up innovative and collaborative practices that sustain the excellence and relevance of higher education, as these will strengthen educational institutions and prepare learners for the workplace of the future.

Link to presentation material: https://events.development.asia/materials/201 71212/hong-kong-university-science-and-technology.

\section{References}

Altbach, P. G., \& Salmi, J. (2011). The road to academic excellence: The making of world-class research universities. Washington, DC: IBRD/World Bank.

Asian Development Bank (ADB). (2014). Innovative strategies in higher education for accelerated human resource development in South Asia. Manila: ADB.

Bentaouet Kattan, R., Macdonald, K. A. D., \& Patrinos, H. A. (2018). Automation and labor market outcomes: The pivotal role of high-quality education (English). Policy Research working paper; no. WPS 8474. Washington, DC: World Bank Group. Retrieved from http://documents.worldbank.org/curated/en/356581528983322638/Automation-and-labormarket-outcomes-the-pivotal-role-of-high-quality-education.

Cheng, Y., Wang, Q., \& Liu, N. C. (Eds.). (2014). How world-class universities affect global higher education influences and responses. Rotterdam: Sense Publishers.

Kao, I., Shamash, Y. A., \& Kim, C. (2013, June). Establishing an American global campus in SUNY Korea: Challenges and excitement in preparing global engineers. Paper presented at 2013 ASEE International Forum, Atlanta, Georgia. https://peer.asee.org/17228.

Park, S. J. (2016). How to innovate higher education in developing countries? Presented at the 2016 ADB International Skills Forum.

Penprase, B. E. (2018). The fourth industrial revolution and higher education. In N. Gleason (Ed.), Higher education in the era of the fourth industrial revolution. Singapore: Palgrave Macmillan.

Postiglione, G. A. (2011). The rise of research universities: The Hong Kong University of Science and Technology. In P. G. Altbach \& J. Salmi (Eds.), The road to academic excellence: The making of world-class research universities (pp. 63-100). Retrieved from http://siteresources.worldbank.org/EDUCATION/Resources/278200-1099079877269/547 664-1099079956815/547670-1317659123740/Chapter3.pdf.

Postiglione, G. A. (2013). Anchoring globalization in Hong Kong's research universities: Network agents, institutional arrangements, and brain circulation. Studies in Higher Education, 38(3), $345-366$.

Times Higher Education. (2016). Korea's internationalization challenge: An interview with the president of the Korea Advanced Institute of Science and Technology. Retrieved from https://www.insidehighered.com/news/2016/04/21/interview-president-koreaadvanced-institute-science-and-technology. 
United Nations Department of Economic and Social Affairs (UNDESA). (2017). The impact of the technological revolution on labour markets and income distribution. Retrieved from https://www.un.org/development/desa/dpad/wp-content/uploads/sites/45/public ation/2017_Aug_Frontier-Issues-1.pdf.

Wang, Q., Cheng, Y., \& Liu, N. C. (Eds.). (2013). Building world-class universities: Different approaches to a shared goal (1-10). Rotterdam: Sense Publishers.

The views expressed in this Chapter are those of the authors and do not necessarily reflect the views and policies of the Asian Development Bank (ADB) or its Board of Governors or the governments they represent.

ADB does not guarantee the accuracy of the data included in this Chapter and accepts no responsibility for any consequence of their use. The mention of specific companies or products of manufacturers does not imply that they are endorsed or recommended by ADB in preference to others of a similar nature that are not mentioned.

By making any designation of or reference to a particular territory or geographic area, or by using the term "country" in this Chapter, ADB does not intend to make any judgments as to the legal or other status of any territory or area.

This work is available under the Creative Commons Attribution 3.0 IGO license (CC BY 3.0 IGO) https://creativecommons.org/licenses/by/3.0/igo/. By using the content of this Chapter, you agree to be bound by the terms of this license. For attribution, translations, adaptations, and permissions, please read the provisions and terms of use at https://www.adb.org/terms-use\#openac cess.

This CC license does not apply to non-ADB copyright materials in this Chapter. If the material is attributed to another source, please contact the copyright owner or publisher of that source for permission to reproduce it. ADB cannot be held liable for any claims that arise as a result of your use of the material.

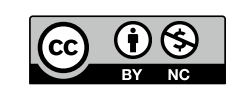

